\title{
Possible Strategies to be Considered to Realise the Inclusion of Learners with Visual Impairment; A Case Study of Secondary Schools in Ethiopia
}

\author{
Kahsay Hailu Negash* \\ Department of Inclusive Education, College of Education, University of South Africa, Pretoria, South Africa \\ *Corresponding Author: Kahsay Hailu Negash, Department of Teacher Education, Institute of \\ Pedagogical Sciences, Mekelle University, Mekelle,Tigrai.Emails: kahane2019@gmail.com
}

\begin{abstract}
This article reports on a case study that investigated possible strategies that can be used to promote the inclusion of learners with visual impairment in Ethiopia. Two Secondary Schools were selected and a qualitative research design was employed. The research participants of the study were the 2 school principals, 4 teachers and 24 learners. Data was generated through one-on-one interviews with teachers and the two principals and focus group discussion with learners. Data gathered were analysed by a constructivist paradigm. The findings show that the strategies that can be used to include learners with visual impairment include accepting diversity by the school community, teachers' inclusion of the learners in their classrooms and making classroom adaptations such as learning environment and instructional adaptations. In addition, this article has come up with other strategies to include learners with visual impairment including encouraging cooperative learning, peer tutoring, collaborative teaching and consultation like co-teaching and using assistive technologies and materials. However, it is found that teachers are not using the above mentioned inclusive teaching strategies in their classrooms. Last but not least, this article will be a good input for future researches. Researchers can also conduct further studies on the same topic in different contexts.
\end{abstract}

Keywords: Inclusion, teaching strategies, regular classrooms, learners with visual impairment, diversity, learners with special educational needs

\section{INTRODUCTION AND BACKGROUND}

The aim of this study on which this article is based was to identify possible strategies that can be employed to promote the inclusion of learners with visual impairment in Ethiopia. The study context was secondary schools of Tigrai, Ethiopia, and it sought to identify practical strategies that school teachers, curriculum developers and policy makers can use to facilitate the inclusion of learners with visual impairments. Secondly, the study sought to contribute to policy development regarding the inclusion of these learners.

From 1991 when Ethiopia became a democratic state, many primary, secondary and tertiary institutions were opened with the intention to increase access to education. Since then, the number of students with special educational needs (SEN) admitted in various institutions has also increased. According to the estimation of the Ministry of Education, there are close to 5 million school-aged children with SEN which includes learners with visual impairments in Ethiopia The figure does not include pre-primary school children since data on it was not collected (MoE, 2015:24). Although Ethiopia signed international agreements on inclusion such as the 2006 UN Convention on the Rights of Persons with Disabilities, Universal Declaration of Human Rights (UNESCO, 1948), the Convention on the Rights of the Child (UNESCO, 1989), the Standard Rules on the Equalisation of Opportunities for Persons with Disabilities (UNESCO, 1993) and the Salamanca Framework for Action on Inclusive Education (UNESCO, 1994), the number of learners with disabilities who have access to education is very small. In light of this, the MoE (2010:74) says that less than $3 \%$ of the total population of children with disabilities in Ethiopia have access to primary education.

From 2006, Ethiopian Ministry of Education shifted from Special Needs Education (SNE) which regards the child with disabilities as problem to inclusive education which focuses on transforming the school system to accommodate all children (MoE, 2012:9). Hence, a shift was needed from SNE 
which emphasises disability as a medical aspect to inclusive education which emphasizes disability as a social aspect.

Although the country adopted inclusive education in 2006, there are limitations in the inclusion of learners with special educational needs including those with visual impairment (MoE, 2012:10). In a general sense, inclusive education means creating learning environments where all children can learn together and be supported to achieve positive learning outcomes. Although the move to adopt inclusive education is applauded, the limitation is that research suggests that teachers still face difficulties in teaching learners with diverse educational needs in spite of their countries adopting inclusive education (Tirussew, 2005:109; Ntombela, 2011; Kahsay, 2017:169).To meet the learning needs of all, teachers need knowledge and skills to implement different teaching strategies (Michel, 2008:31).

\subsection{Diversity in Education}

The introduction of inclusive education in many countries, Ethiopia included, signifies that Ministries of Education acknowledge that learners present numerous learning differences which teachers need to be aware of and to support. These differences are a normal part of life which all teachers need to be able to respond appropriately to. Lewis and Doorlag (2011:69-70) and Smith, Polloway, Patton and Dowdy (2008:36) state that $21^{\text {st }}$ century classrooms are becoming very diverse. As a result, regular school teachers have had to fulfill many roles and responsibilities since the introduction of inclusive education (Kuyini, Yeboah, Das, Alhassan\& Mangope, 2016:1011). Lewis and Doorlag (2011:80) claim that in today's classrooms teachers should respond in accordance to their learners' needs. As such, teachers are required to understand issues of diversity and to have strategies that can be used to address the learning needs of all their students.

To be able to respond appropriately to learner diversity, teachers are required to have "unique competencies" to teach all learners in their inclusive classrooms. Ainscow and Goldrick (2010) cited in Kuyini, et al. (2016:1011) state that such competencies include skills and knowledge of approaches and strategies of teaching in regular classrooms. However, the reality in schools, as highlighted by scholars such as Florian and Linklate (2010:369) and Mariga, McConkey and Myezwa (2014:90) is that teachers tend to lack knowledge and skills to teach in inclusive classrooms. In addition, studies by Tirussew (2005:109) and Awetash (2015:77) and Kahsay (2017:169) show that teachers are not receiving appropriate training and lack teaching strategies to include learners with impairments. The focus of this article is on strategies that teachers can use to promote the inclusion of learners with visual impairments in inclusive classrooms.

\subsection{Strategies that Promote Inclusion}

Boyle and Topping (2012:165) maintain that teachers play a critical role in the educational life of the learners during their stay in schools. It is in that vein that Loreman, et al. (2005:15) argues that a positive attitude towards learner diversity is important as a step towards inclusion. Therefore, it is important that teachers are aware of diversity in their classrooms and that they receive support in the form of continuous professional teacher development. There are a number of strategies highlighted in literature that can be used to promote the inclusion of learners with visual impairments. Six of those strategies are teacher development, classroom adaptations, cooperative learning, peer tutoring, collaborative teaching and using assistive technologies and materials.

\subsubsection{Teacher Development}

One of the main strategies that ministries of education use to enhance teachers' competencies and knowledge to support the inclusion of learners with VI is teacher development. UNESCO (2005:21) argues that there is a direct relationship between teacher development and inclusion. If teachers are provided with the opportunities to learn how to include learners with special educational needs, then they will be confident to include all learners in the teaching and learning process.

Teacher development is important in raising awareness about learner diversity and changing perceptions and attitudes to difference.

\subsubsection{Curriculum Adaptation}

Likewise, teachers should know how to adapt their instructions and the classroom environments so as to meet their learners' educational needs. Hallahan, Kauffman and Pullen (2012:37) point out that 
making adaptation is one of the strategies to include learners with special educational needs such as learners with visual impairments. Asrat (2013:61) also believes that teachers are one of the responsible people for either instructional or classroom environment adaptations. This is why teachers need to receive trainings on how to make adaptations so as to include all learners in their classrooms.

\subsubsection{Cooperative Learning}

In addition, Hallahan, et al. (2012:37), Jha (2002:10) and Demetros (2007:26) show that cooperative learning is one of the strategies that can be used to include learners with special educational needs including learners with visual impairments in regular classrooms. Mwakyeja (2013:26) claims that cooperative learning is a strategy that teachers can apply in their classrooms to include learners with visual impairments. A late study by Slavin (1994:12) also argues that cooperative learning is a research proven inclusive teaching strategy.

\subsubsection{Peer Tutoring}

What is more, according to Jha (2002:10) and Demetros (2007:26) peer tutoring is one of the strategies that teachers can be trained on and implement in their inclusive classrooms. Hallahan, et al. (2012:37) state that peer tutoring is a research proven strategy which is helpful to include learners with visual impairments or learners with other types of impairments.

\subsubsection{Collaborative Teaching}

Again, collaborative teaching is another strategy that can help to include learners with visual impairments in regular classrooms. Murawski (2009:12) advises general and special education teachers to work together starting from lesson planning stage in order to include learners with special educational needs. In addition, Mastropieri and Scruggs (2010: 44-45) advise paraprofessionals to help both general and special education teachers. In general, collaborative work which leads to collaborative teaching in schools is crucial to realise the inclusion of learners with visual impairments.

\subsubsection{Using Assistive Technologies and Materials}

Equally important is to give attention to assistive technologies and materials. Assistive technologies and materials are helpful for learners with sensory impairments like learners with visual impairments. A study by Lewis and Doorlag (2011:306) found out that assistive technologies and materials are extremely important for learners with visual impairments or other learners with sensory impairments. Smith, et al. (2008:326) add that assistive technologies and materials ease learners with visual impairments learning by which their inclusion in the classroom is secured to the minimum.

Many researches and literature reviews have been consulted on the issue under discussion including the previously discussed ones. Most of the studies conducted in the area such as studies by Mbelu (2011) and Bishop and Rhind (2011) focus on disabilities and impairments but the majority of the studies highlight barriers to the inclusion of learners with visual impairments in schools and few give attentions to how to include the learners. This initiated the researcher to conduct a research in the area. The researcher was also taught by a teacher with visual impairment at secondary school and this prompted him in assessing possible strategies to be considered to realise the inclusion of learners with visual impairments in Ethiopia. The study sought to address this research question: What strategies can be employed to facilitate the inclusion of learners with visual impairment in secondary schools in Ethiopia?

\section{THEORETICAL FRAMEWORK}

Armstrong, Armstrong and Spandagou (2010:24), Tirussew (2005:112) and Asrat (2013:59) note that the notion of inclusive education emanates from human right and social justice. Hence, inclusive education has been promoted in many international documents such as United Nations Convention on the Rights of the Child (1989), the Universal Declaration of Human Rights (1948) and the Convention on the Rights of Persons with Disabilities (2006). As a result, the study was framed with John Rawl's theory of justice. Literature shows that there have been unfair distributions of resources and service in the education sector for a long period of time due to lack of fair and just education system. According to John Rawl's theory of justice, people with impairments have the right to access to social benefits. In other words, learners with impairments like learners with visual impairments have the right to 
education. Despite the theory's criticism by scholars including Terzi (2010:10) for its less emphasis on education, the theory is one of the noticeable theories which can be used in education. Studies $b$ many scholars such as Asch (2001:318-319) show that disability is not a health problem rather it is a right and social problem. Consequently, the education of learners with visual impairment should be viewed from social justice aspect than health aspect by which learners with visual impairment should be included in regular schools that segregated in special schools.

\section{MATERIALS AND METHODS}

The research methodology used in the study was qualitative in nature. This research was conducted in Mekelle, the capital city of Tigrai Regional State in Ethiopia. Two secondary schools were selected from the city for this research article. The two schools were selected because they enrolled learners with visual impairments and they were better resourced than the other schools in the city.

\subsection{Research Population and Sampling}

Regarding the population of the schools, School A had one main school principal, 76 teachers and 2645 grade nine and ten learners. Out of the 2645 learners, there were 26 blind learners but the number of low-vision learners was not recorded by the school. Of these total populations of the school, one school principal, two teachers and 12 learners participated in the in the study as respondents. Again School B had one main school principal, 97 teachers and 2977 learners of which 25 were learners with visual impairments while the number of low-vision learners was not identified by the school. Out of the total population of the school, one school principal, 2 teachers and 12 learners participated in the study. To make more clarification on the number of learners who participated in the study, 12 visually-impaired of which the two were low-vision and 12 sighted learners were included. In total, 30 individuals took part in the study as respondents. The justification for including sighted learners in the study as respondents was to see their interaction with learners with visual impairments and check their awareness towards learners with visual impairments. Another reason was also to investigate their opinions whether they are happy to learn with learners with visual impairments.

In order to select the schools and respondents, purposive sampling was employed. The two schools were selected because they enrolled and were teaching learners with visual impairments and were better resourced compared to other schools in Mekelle city. Principals were selected as respondents because they are the ones who are responsible for the implementation of inclusive education in the schools. Teachers were chosen as respondents since they are the ones who apply inclusion in the classrooms and learners were selected since the implementation of inclusive education is practiced on them. During the selection process, teachers with better and longer experience of teaching classrooms with learners with visual impairments were chosen and focus group discussion (FGD) respondents were selected based on their experience of learning with learners with visual impairments, academic performance, and their participations in school activities.

Regarding the gender of the respondents, both principals and teachers were males because there were no female staff members who fulfil the criteria. However, the learner respondents were from both genders.

\subsection{Delimitation and Limitations}

This article focuses on the possible strategies to be considered to realise the inclusion of learners with visual impairments. So it emphasizes only on the strategies to include those learners. Again, the article is delimited to learners with visual impairments which include both blind and low-vision learners. Hence, the article has a limitation on its generalisability to other types of impairments.

On the other hand, the study was conducted in one of the regional states in Ethiopia i.e. Tigrai Regional State. Of the many cities in Tigrai, it is again delimited to the capital city of the regional state called Mekelle. Though there are many schools in Mekelle, only two secondary schools are selected for the study. Therefore, the article is delimited both in the study area and in its scope.

The article is also delimited in its research design and methodology. This research article followed a qualitative research design with constructivist paradigm. The data collection instruments were also limited to three which included interview, FGD and observation. 


\subsection{Data Collection Procedure}

To conduct the study, first a letter to the Ethiopian Ministry of Education was written for permission. After permission was granted, other letters to the targeted schools were written for the same purpose. Then, the schools allowed the researchers to conduct the study. But there was another step to be done that was preparing consent and assent letters to respondents. By the letters, the respondents agreed to participant in the study. Then, the interviewer created a rapport with the respondents and started collecting the needed data. Data for this research article was collected by three data collection instruments namely; interview, FGD and observation. Interviews were held with 2 school principals and 4 teachers. The interviews were held inside the school compounds in work hours. In addition, FGD was held with 24 learners of which 12 were learners with visual impairments and the other 12 were sighted fellow learners. The FGD participants were grouped in to four according to their categories which was learners with visual impairments were grouped together and sighted learners were grouped in their own group with two learners with visual impairments groups having six learners each and the same grouping of sighted learners. This was intentionally do so as to allow all the learners to express their feeling without being afraid of the opposite group friends. The sighted learners and learners with visual impairments were asked different questions. Interviews with the school principals, teachers and focus group discussants were mostly asked different questions but with some similar questions for cross checking. Probing was also used to explore and expand the views of the respondents. In addition, observation was employed to gather data from the real school and classroom settings. After a permission was granted from four teachers (two teachers from each school), a non-participant classroom observation was done. During the classroom observation, the observer did not interrupt, engage or influence the teaching-learning process other than collecting the necessary data.

\subsection{Data Analysis}

Data for this article were collected through interviews, FGD and observation. All interview and FGD data were audio recorded and transcribed for later use whereas observation data were collected in hard copy. After the interview and FGD were transcribed they were organised together with observation data for reading. Then, the researchers read the data thoroughly in order to familiarise themselves with the data. Next, data collected by the individual instruments were separately grouped under different themes. Three steps of data coding that are open, axial and selective coding were used to code the data during analysis.

\subsection{Measures to Ensure Trust Worthiness}

To increase the trustworthiness of the findings, data were triangulated by collecting through three types of data collection instruments. The data were cross-checked to develop the themes. In addition, since more cases increase the validity and generalizability of the study, two school cases were used in this research article. Contrary data were also included in the study to increase the credibility of the findings. Besides, the researchers spent enough time in the study area and schools to better understand the situation in-depth. Again, external reviewers and member checkers read the entire article and assessed it and their feedbacks were considered.

\section{RESULTS AND DISCUSSION}

\subsection{Individual Interviews (Principals and Teachers) and Observation Community Awareness Regarding Learners with Visual Impairment}

The principal of School B reported that his school creates awareness about inclusive education and visual impairment in meetings, through its school mini media, sub-city mini media and Mekelle city FM radio while this is not the case in School A. Above all, all the interviewed participants explained that learners with visual impairments have been making the community aware by engaging themselves in different activities. Some of the learners play soccer games, others are athletes and even represented Tigrai Regional State at a national level, and some are clever learners in their education. The researchers have also seen the learners reading poems in front of their fellow earners, playing games and actively participating in the classrooms. 
But the outside school community has little awareness on how learners with visual impairments learn in schools. With regards to awareness School B principal said that, "Our society doesn't know how the visually-impaired students learn in the class and how these students are active like others. They ask them how they learn because they don't have any text or exercise book." In relation to the culture of the society, the principal further said that:

In our culture, the society does not support them believing that their impairment comes from God and if they support them, they fear that the impairment may go with them to their homes. ... most of our society is not educated. They have different beliefs and they believe that the impairment comes from God or from others.

The teachers also shared the principal's view and a participant teacher stated that the society does not have awareness about visual impairment. A teacher responded that "...our people do not understand them easily." In addition, the principal stated that "the culture of the society is a barrier to the inclusion of the learners inside or outside the school. "In light of this, the MoE (2012:43) states that Ethiopian communities have negative attitudes towards persons with disabilities including learners with visual impairments. Again, a study by Etenesh (2002: xi) shows that learners with visual impairments are excluded by the community. The researchers have also observed that learners with visual impairments walk to schools alone or with their similar impairment fellows and sit inside and outside classrooms together.

\subsection{Teachers' Use of Strategies to Include Learners with Visual Impairment}

According to School A principal, there is a 1:5 seating arrangement for the learners in his school. He said that learners with visual impairments are grouped with sighted learners in the seating arrangement. Two teacher participants also agreed on the principal's idea. A teacher said that, "...the seating arrangement is in a network group i.e., 1 to 5 network group. Then they are given different exercises to discuss on. After that they report to the class. That's a good situation." Having such grouping is good as Westwood (2011:40) and Mwakyeja (2013:26) argue that putting learners with disabilities like learners with visual impairments in mixed ability groups help the learners better learn and be included.

Classroom teachers and the principals reported that learners with visual impairments sit at the front in classrooms. However, due to large class size, the participants and observation results indicate that learners with visual impairments were not included in group activities. A strategy School B teachers use to help learners with visual impairments as they reported is that they allow the earners to ask them questions after class for clarification. A teacher from School B also reported that he uses peer learning in his classrooms to include learners with visual impairments. In support of this, Hornby, et al. (2004:234) states that some teacher use peer tutoring to include all learners in their classrooms. But the teacher said that usually learners with visual impairments are dominated in classrooms and some teachers do not consider them while teaching. For example, the teacher said that he writes notes on the board and forgets learners with visual impairments. However, scholars such as Michel (2008:60) and Hallahan, et al. (2012:37) advise that teachers should avoid such exclusion experiences by using peer tutoring, collaborative teaching and consultation, using assistive technologies and materials.

\subsection{Teacher and Learners Use of Assistive Technologies and Materials}

Principals of both school said that their schools have computers for their learners. However, School A principal reported that the computers had soft ware and books uploaded on them. On the other hand, School B principal said that his school gave tape recorders and Plasma TV recorded materials to learners with visual impairments. Again, both the school principals complained that the computers in their schools are not enough. School B principal also reported that, "the school does not have assistive technologies for both the learners and teachers". The interviewed teachers also stated that there are no enough available assistive technologies and materials that teachers and learners can use in the schools. School B interviewed teachers said that totally blind learners do not even have Braille and audio recorders. A teacher from the school pointed out that "since blind learners do not have Braille, they are not able to take notes in class. The learners do not have audio-recorders as well". Similarly a teacher from School A School said, "we do not have access to technologies such as computers". The teachers further said that the learners do not take notes in classes. School a interviewed teachers 
also said that they do not have access to computers. The teachers complained that there are very few computers in the school and some of the computers do not work. Furthermore, the teachers pointed out that the Plasma TV screens installed in the schools are not functioning and there are no audio recorded books for learners with visual impairments. The researchers' observation results also show that there are some computers in the two schools but they are not enough, some are not working and they do not have the necessary soft ware installed on them. But computers in school B have some audio recorded materials from textbooks. In general, teachers and learners have lack of access to assistive technologies and materials though scholars such as Downing and Cheng (2003:56) and Smith, et al. (2008:326) recommend both teachers and learners should have access to the technologies and materials.

\subsection{Focus Group Discussion (Learners) and Observation Teachers' Use of Strategies to Include Learners with Visual Impairments}

Mariga, et al. (2014:117) put that classroom teachers should organise groups by which everyone benefits equally. FGD respondents reported that though their teachers group sighted and learners with visual impairments together, learners with visual impairments are dependent on their sighted peers. A learner said;

Teachers do not help us in a special way but we sometimes discuss with others in groups. There is a 1 to 5 networking among learners but it is not functional. Teachers do not tell us to be in groups and help each other or discuss in groups, but we find clever learners by ourselves and discuss with them outside the classroom.

Another learner said that "They (teachers) don't let us work with others in groups. Unless we join groups when they instruct the class to work in groups, teachers do not help us."

Discussants from School B added that even when teachers tell learners with visual impairments to sit with other learners, the teachers focus on sighted learners. They further said the teachers forget the attendance of learners with visual impairments in classrooms. However, a low-vision learner from School B reported that some teachers help low-vision learners by writing notes in big letters on the chalkboards. However, the discussants reported that some teachers make learners with visual impairments to sit at the front in classrooms. In support of this Smith, et al. (2008:325) and English (2011:305) state that such seating arrangements are advisable to use in classrooms. But in general, the FGD participants stated that they were receiving better support from their teachers in primary schools compared to the support they receive from their current secondary school teachers.

Moreover, the learners reported that their teachers do not use teaching strategies such as peer learning, collaborative teaching and cooperative learning. A sighted learner said that "It is not common for a learner to teach other peer learners. There is no collaborative learning but it rarely happens, but it is possible to say that there is no collaborative learning." The researchers' observations in the school also show that teachers are not using inclusive teaching strategies such as the above mentioned ones. In relation to this, a study by Demetros (2007:viii) conducted in Ethiopia shows that teachers do not use inclusive teaching strategies due to lack of appropriate trainings, large class size, workloads, and lack of space in the classrooms.

\subsection{Teachers and Learners us of Technologies and Materials}

Lewis and Doorlag (2011:306) see that assistive technologies such as computers, phones, television and audio recorders are helpful to fulfil the educational needs of learners. In light of this A sighted learner from School B said that "There are around 15 computers and we are 58." Another learner also said, "There are very few computers in our school. Four or five learners use one computer at the same time." However, FGD respondents reported that both teachers and learners use of the technologies is limited. In relation to teachers' use of technologies, a learner said that, "They (teachers) don't use any king of technologies." Researchers' observation results also show that though there are very few assistive technologies available in the schools, most of them are not functional and the learners and teachers do not know how to use them except some. Especially the computers installed in the schools are few in number, broken, do not have necessary software and are infected by viruses. Learners with visual impairments also said that when they want to audio record the teachers' lessons, the teachers are not voluntary. As a result, learners with visual impairments 
complained that, "Since there is lack of technological access, we are not able to listen to audio recorded materials." The above data signify that both teachers and learners have limited use of assistive technologies and the learners' inclusion in negatively affected.

\section{CONCLUSION}

The aim of this study on which this article is based was to identify possible strategies that can be employed to promote the inclusion of learners with visual impairments in Ethiopia. The research findings show that the inside school community has better awareness about visual impairment and inclusion than the outside community. The outside school community has wrong beliefs towards learners with visual impairments. However, there are school community members including teachers who are not aware about the matters. School B has made efforts to aware the inside and outside school community through different medias but mostly its learners with visual impairments as in School A aware the communities by engaging themselves in various activities such as sports.

With regards to teachers' use of strategies to include learners with visual impairments, the schools have a 1:5 seating arrangements by which all learners are expected to sit in groups. However, learners with visual impairments do not actively participate in the groups and sighted learners are dominant. In addition, most of the classrooms in the schools especial in School A are crowded with large number of learners. In such classrooms, learners' with visual impairments' inclusion is very limited. One of the strategies few teachers use to help learners with visual impairments is allowing the learners to ask questions to their teachers after class. Again, a teacher from School B said that he uses peer learners. Other than these two strategies, the results show that, teachers are not using any especial teaching strategies to include learners with visual impairments in their classrooms.

The article results also indicate that there is a limitation in teachers and learners use of assistive technologies and materials in the schools. Results show that there are very few computers in the schools. Out of these few computers, some are broken, some have viruses, and most of the teachers and learners do not know how to use them. Those computers that are working also do not have materials uploaded on them. Only in School B, some computers have audio recorded textbook chapters prepared by voluntary teachers. Similarly, there are Plasma TV screens in the schools which could help the learners but they are not working. In addition, learners with visual impairments do not have the basic materials such as Braille and audio recorders.

The evidences from this research article show secondary school teachers are not using teaching strategies to include learners with visual impairments in secondary schools due to factors including lack of professional training, professional collaboration, large class size and limited access to assistive technologies and materials. This implies that learners with visual impairments are not included in Ethiopian secondary schools particularly in Mekelle City, Tigrai.

The significance of the article is that it extends the local knowledge gained through his article to the global knowledge of inclusive education and inclusion.

On the other hand, a number of limitations need to be considered in this article. First, the article sought in to one type of impairment that is visual impairment. Second, the article was multiple case study article and is limited in scope by which it is difficult to generalize the research results to other contexts. Third, finding similar research papers to use them as references was a challenge.

Finally, further research is needed in the same or related inclusion topic in a different context with multiple cases and quantitative data.

\section{REFERENCES}

[1] Armstrong, A., Armstrong, D. \& Spandagou, L. 2010. Inclusive education: International policy and practice. London: Sage.

[2] Asch, A. 2001. Disability, bioethics, and human rights. In Albrecht, G., Seelman, K. \& Bury, M. (Eds). Handbook of Disability Studies. Thousand Oaks: Sage.

[3] Asrat, D. 2013. Factors affecting the implementation of inclusive education in primary schools of Bahir Dar Town Administration. Education Research Journal, 3(3):59-67.

[4] Awetash, H. 2015. Psychosocial and educational challenges and opportunities of students with visual impairment: The case of Adimahleka Primary School in Adwa Town. Unpublished Master's Thesis. Addis Ababa: Addis Ababa University. 
[5] Bishop, D. \& Rhind, D. 2011. Barriers and enablers for visually-impaired students at a UK higher education institution. British Journal of Visual Impairment, 29 (3): 177-195.

[6] Boyle, C. \& Topping, K. 2012. What works in inclusion? Berkshire: Open University Press.

[7] Demetros, M. 2007. Challenges of teaching visually-impaired students in an inclusive classroom: The case of two selected primary schools in Amhara Region. Unpublished Master's Thesis, Addis Ababa: Addis Ababa University.

[8] English, K. 2011. Teaching students with visual and hearing impairment. In Lewis, R. \& Doorlag, D. (Eds.) Teaching Students with Special Needs in General Education Classrooms. Upper Saddle River: Pearson Education.

[9] Etenesh, W. 2002. Attitudes of the sighted on the education, employment and marriage of the visuallyimpaired in Addis Ababa. Unpublished Master's Thesis. Addis Ababa: Addis Ababa University.

[10] Florian, L. \&Linklater, H. 2010. Preparing teachers for inclusive education: using inclusive pedagogy to enhance teaching and learning for all, Cambridge Journal of Education, 40:4, 369-386. Available at http://dx.doi.org/10.1080/0305764X.2010.526588 (Online). [Accessed on July 14, 2016].

[11] Hallahan,D., Kauffman, J. \& Pullen, P. 2012. Exceptional learners: An introduction to special education. (12th ed.). Upper Saddle River: Pearson Education.

[12] Hornby, G., Atkinson, M. \& Howard, J. 2004. Peer/parent tutoring: is it effective? In Mitchell, D. (Ed.) Special Educational Needs and Inclusive Education: Major Themes in Education. Volume III, Assessment and Teaching Strategies. New York: Routledge.

[13] Jha, M. 2002. Barriers to access and success: Is inclusive education an answer? Paper presented at the PanCommonwealth forum on open learning: Open learning: transforming education for development, 29 July - 2 August 2002, Durban, South Africa [Online]. Available at www.col.org/pcf2/papers\%5Cjha.pdf. [Accessed 06 June 2013].

[14] Jonker, J. \& Pennink, B. 2010. The essence of research methodology: A concise guide for master and PhD students in management science. Berlin: Springer-Verlag.

[15] Kahsay, H.N. 2017. The Inclusion of learners with visual impairment in Ethiopian Secondary Schools. Unpublished Doctoral Thesis. University of South Africa. Pretoria (Online). Available at http//:hdl. handle.net/10500/23484. [Accessed November 06, 2017].

[16] Kothari, C.R. 2004. Research methodology: Methods and techniques. New Delhi: New Age International.

[17] Kuyini, a.b., Yeboah, K.A., Das, A.K., Alhassan A.M., \& Mangope, B. 2016. Ghanaian teachers: competencies perceived as important for inclusive education, International Journal of Inclusive Education, 20:10, 1009-1023, DOI:10.1080/13603116.2016.1145261 (Online). Available at https://doi.org/10.1080/ 13603116.2016.1145261. [Accessed on November 27, 2018].

[18] Lewis, R. \& Doorlag, D. 2011. Teaching students with special needs in general education classrooms. New Jersey: Pearson Education.

[19] Mariga, L., McConkey, R. \& Myezwa, H. 2014. Inclusive education in low-income countries: A resource book for teacher educators, parent trainers and community development workers. Cape Town: Atlas Alliance and Disability Innovations Africa.

[20] Mastropieri, M. \& Scruggs, T. 2010. The inclusive classroom: Strategies for effective differentiated instruction. (4th ed.) Upper Saddle River: Pearson Education.

[21] Mbelu, S.E. 2011. Implementation of inclusive education in the Umgungundlovu District of Education in Kwazulu-Natal. Unpublished Master's Thesis. University of South Africa, Pretoria.

[22] Ministry of Education, Federal Democratic Republic of Ethiopia. 2006. Special needs education program strategy; Emphasizing inclusive education to meet the UPEC and EFA goals. Addis Ababa: Ministry of Education.

[23] Ministry of Education, Federal Democratic Republic of Ethiopia. 2010. Education sector development program IV (ESDP-IV), Program Action Plan (PAP). Addis Ababa: Ministry of Education.

[24] Ministry of Education, Federal Democratic Republic of Ethiopia. 2012. Education statistics annual abstract. Addis Ababa: Ministry of Education: Education Management Education Systems.

[25] Ministry of Education, Federal Democratic Republic of Ethiopia. 2015. Education sector development program V (ESDP-V), Program Action Plan (PAP). Addis Ababa: Ministry of Education.

[26] Mitchell, D. 2008. What really works in special and inclusive education: Using evidence based teaching strategies. London: Routledge.

[27] Murawski, W. 2009. Collaborative teaching in secondary schools: Making the Co-teaching marriage work! [Online]. Available at http://dx.doi.org/10.4135/9781452219370.n1. [Accessed 28 May 2014]. 
[28] Mwakyeja, B. 2013. Teaching students with visual impairments in inclusive classrooms: A case study of one secondary school in Tanzania. Unpublished Master's Thesis, Department of Special Needs Education, Faculty of Educational Sciences, University of Oslo [Online]. Available at https://www.duo.uio.no/ bitstream/handle/10852/MasterxsxThesis.pdf. [Accessed 24 January 2014].

[29] Ntombela, S. 2011. The Progress of Inclusive Education in South Africa: Teachers' Experiences in a Selected District of KwaZulu-Natal, 4(5). Sage Publishing.

[30] Slavin, R.1994. A practical guide to cooperative learning. Boston: Allyn and Bacon.

[31] Smith, E., Polloway, E., Patton, J. \& Dowdy, C. 2008. Teaching students with special needs in inclusive settings. Boston: Pearson.

[32] Terzi, L. 2010. Justice and equality in education: A capability perspective on disability and special educational needs. London: Continuum International.

[33] Tirussew, T. 2005. Disability in Ethiopia: Issues, insights and implications. Addis Ababa: Addis Ababa University Printing Press.

[34] United Nations Educational, Scientific and Cultural Organization. 2005. Guidelines for inclusion: Ensuring access to education for all. Paris, UNESCO.

[35] United Nations Educational, Scientific and Cultural Organization. 2005. Guidelines for inclusion: Ensuring access to education for all. Paris, UNESCO.

[36] Westwood, P. 2011. Common sense methods for children with special educational needs (6th ed.) London: Routledge.

\section{AUTHOR'S BIOGRAPHY}

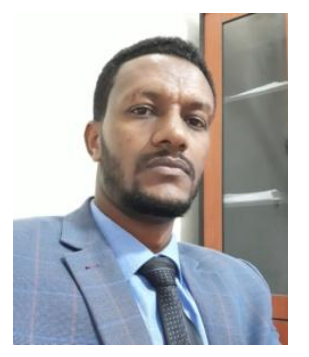

Dr. Kahsay Hailu Negash, has earned his Bachelor's Degree in English Education and Master's Degree in English Language Teaching. Besides, hepursued his doctorate degree in Inclusive Education. In addition to his degrees, Dr Kahsay has more than 12 years work experience. He has worked in Higher Education Institutions both inside and outside his home country Ethiopia. Dr. Kahsay has functioned as Higher Diploma Leader, Department Head, Director for Disability Support and Study Directorate Office and many more positions. Furthermore, he has been highly engaged in teaching, research and community service works. As a result, he has produced research works in the areas of English Language Teaching, Special Needs Education and Inclusive Education. In addition, Dr Kahsay has numerous work experiences with local and international NGOs. Currently, Dr Kahsay is working at a university as assistant professor and Vice President for Research and Community Service office.

Citation: Kahsay Hailu Negash. "Possible Strategies to be Considered to Realise the Inclusion of learners with visual impairment; A Case Study of Secondary Schools in Ethiopia". International Journal of Humanities Social Sciences and Education (IJHSSE), vol. 7, no.1, 2020, pp. 93-102. doi: http://dx.doi.org/10.20431/23490381.0701011.

Copyright: () 2020 Authors. This is an open-access article distributed under the terms of the Creative Commons Attribution License, which permits unrestricted use, distribution, and reproduction in any medium, provided the original author and source are credited. 